\title{
Processo de britagem e sua influência nas características físicas do agregado graúdo para o concreto reciclado
}

Crushing process and its influence on the physical characteristics of coarse aggregate for recycled concrete

Proceso de trituración y su influencia en las características físicas del agregado grueso para concreto reciclado

\author{
ALMEIDA E SILVA, Danillo ${ }^{1}$ \\ LUNA DE MELO, Carlos Eduardo ${ }^{2}$ \\ 1 Programa de Pós-Graduação - PPG-FAU, Universidade de Brasília, Brasília, Brasil. arq.danillo@gmail.com \\ ORCID: 0000-0001-6402-8086 \\ 2 Programa de Pós-Graduação - PPG-FAU, Universidade de Brasília, Brasília, Brasil. carlosluna@unb.br \\ ORCID: 0000-0003-2160-6776 \\ Recebido em 23/01/2020 Aceito em 18/06/2020
}




\title{
Resumo
}

Diante dos avanços tecnológicos e a necessidade de melhores resultados a um menor custo, a indústria da construção civil vem tentando aperfeiçoar ou mitigar algumas propriedades do agregado graúdo para concreto, e, estas propriedades tendem a exercer efeito no desempenho do concreto. A influência que o mecanismo de britagem exerce na característica do agregado graúdo tendem a ser eliminada ou melhorada, e, isso faz com que pesquisas sejam desenvolvidas neste sentido, e, somada a escassez de recursos naturais, se faz necessário o conhecimento das propriedades de cada insumo do concreto, para que se possa obter os melhores resultados do produto final. Certas características do agregado graúdo tendem a influenciar as propriedades mecânicas do concreto, e o conhecimento dos fatores influentes nas características do agregado, permite um maior controle tecnológico do concreto, o que torna possível o alcance de um produto com melhor qualidade e a um menor custo, com melhora de sua qualidade e resistência.

Palavras-Chave: Britagem; Características; Agregado Natural; Agregado Reciclado.

\begin{abstract}
In face of technological advances and the need for better results at a lower cost, the construction industry has been trying to improve or mitigate some properties of the coarse aggregate for concrete, and these properties tend to have an effect on the performance of the concrete. The influence that the crushing mechanism has on the coarse aggregate characteristic tends to be eliminated or improved, and this means that research is developed in this sense, and, in addition to the scarcity of natural resources, it is necessary to know the properties of each concrete input, so that the best results of the final product can be obtained. Certain characteristics of the coarse aggregate tend to influence the mechanical properties of the concrete, and the knowledge of the factors influencing the characteristics of the aggregate, allows a greater technological control of the concrete, which makes it possible to reach a product with better quality and at a lower cost, with improvement of its quality and resistance.
\end{abstract}

Key-Words: Crushing; Characteristics; Natural Aggregate; Recycled Aggregate.

\section{Resumen}

Frente a los avances tecnológicos y la necesidad de mejores resultados a un costo menor, la industria de la construcción ha estado tratando de mejorar o mitigar algunas propiedades del agregado grueso para el concreto, y estas propiedades tienden a tener un efecto en el rendimiento del concreto. La influencia que tiene el mecanismo de trituración en la característica de agregado grueso tiende a eliminarse o mejorarse, y esto significa que la investigación se desarrolla en este sentido y, además de la escasez de recursos naturales, es necesario conocer las propiedades de cada uno. aportación concreta, para que se puedan obtener los mejores resultados del producto final. Ciertas características del agregado grueso tienden a influir en las propiedades mecánicas del concreto, y el conocimiento de los factores que influyen en las características del agregado, permite un mayor control tecnológico del concreto, lo que permite alcanzar un producto con mejor calidad y a un menor costo, con mejora de su calidad y resistência.

Palabras clave: trituración; Características; Agregado natural; Agregado Reciclado 


\section{Introdução}

O concreto é o produto mais consumido no mundo (MEHTA; MONTEIRO, 2008), depois da água potável e da energia elétrica. No passado, o concreto era praticamente composto por agregado graúdo NBR 7211 (ABNT, 2005), agregado miúdo, cimento e água. Hoje, devido aos avanços tecnológicos e a necessidade do homem de sempre superar seus obstáculos, aprimorando e criando novos conhecimentos, o concreto foi sendo aperfeiçoado para atender as necessidades do homem e a grande demanda por novas tecnologias, sendo composto adicionalmente por aditivos e adições de novos materiais.

As propriedades tão desejadas do concreto fresco e endurecido, como trabalhabilidade, resistência à tração, compressão e módulos estáticos de elasticidade e de deformação à compressão, são norteadas pelas características dos agregados graúdo e miúdo, tais como: forma, textura, dimensão, massa específica, massa unitária, porosidade, sendo que, estas características são influenciadas pelo processo de beneficiamento, conhecido como "britagem".

Os agregados são materiais granares, com forma e volume definidos, com dimensões e propriedades adequadas para uso em obras de engenharia civil. Podem ser classificados levando-se em conta a origem, a densidade e o tamanho dos fragmentos (PARAGUASSU; FRAZÃO, 1998).

Pode-se dizer que em torno de $65 \%$ a $85 \%$ do volume do concreto é composto por agregado graúdo e miúdo (MEHTA; MONTEIRO, 2008), tornado estes, os insumos mais produzidos e consumidos na indústria da construção civil. Com isso, a relativa abundância deste recurso natural já pode ser questionada. Segundo (SILVA, 2012), a disponibilidade de matérias-primas dentro ou em torno dos grandes aglomerados urbanos do país vem diminuindo, em virtude de planejamento inadequado, problemas ambientais, zoneamento restritivo e usos competitivos do solo. A possibilidade de exploração desses recursos está tornando-se relativamente limitada, tornando-se incertas as perspectivas de suprimento futuro. Até o presente momento, o preço relativamente baixo destes insumos deveu-se ao fácil acesso às reservas e às pequenas distâncias de transporte.

O conhecimento das características dos agregados, bem como de suas propriedades físicas e mecânicas, permite uma melhor previsão de seu comportamento como componente do concreto. Com a evolução tecnológica, os critérios de qualificação e seleção dos agregados disponíveis para concreto serão cada vez mais rigorosos, e estes deverão estar inteiramente à disposição da engenharia dos materiais.

Estudos realizados por vários autores (AÏTCIN, 2000; M. C. POWERS, 1953; MEHTA; MONTEIRO, 2008; MENDES, 2002; O'REILLY, 1998; SILVA; GEYER, 2018a, 2018b; SILVA; GEYER; PANTOJA, 2017a, 2017b) são concordes ao afirmar que o procedimento de dosagem de concreto depende das características da forma e superfície dos agregados. Isto significa dizer que depende de sua britagem, rugosidade e textura (MENDES, 2002; SILVA, 2012).

Segundo (SBRIGHI NETO, C; FRAZÃO, 1984), a forma dos agregados graúdos britados está sujeita a influências de mecanismos internos e externos, como propriedades petrográficas do material rochoso, e do processo de britagem utilizado para produção do agregado graúdo.

Vários estudos examinaram o uso de resíduos de concretos e resíduos cerâmicos advindos da construção, como fontes de matéria-prima para uso como agregados graúdos para concreto (AMORIM; BRITO, 2012; GOMES; DE BRITO, 2007; SILVA; DE BRITO; DHIR, 2014). Outras pesquisas abordaram o uso destes resíduos como agregado graúdo e agregado miúdo para concreto (ALVES et al., 2014; STROHER et al., 2017). Brito et. al (AMORIM; BRITO, 2012; BRAVO et al., 2015; GOMES; DE BRITO, 2007; MARTINS; CORREIA; DE BRITO, 2016), possui uma ampla pesquisa no uso do agregado de concreto reciclado para uso em novos concretos.

A importância da pesquisa sobre o mecanismo de britagem do agregado graúdo se faz necessária, pela influência que este processo exerce nas características do concreto, tais como: trabalhabilidade, economia, resistência mecânica. 


\section{Formas de obtenção dos agregados graúdos}

\subsection{Agregado natural}

As rochas, de acordo com seu processo de formação, constituem três grandes grupos: ígneas, sedimentares e metamórficas, cada qual com características peculiares.

Os calcários de origem sedimentares são, em geral, de baixa resistência e pouco indicados como material de construção. Os dolomitos, por sua vez, costumam apresentar características físicas e mecânicas compatíveis com certas funções do material de construção. Os mármores, as ardósias, os gnaisses e os quartzos são os que mais se prestam ao uso como material de construção, com destaque para os gnaisses, que são, dentre estes, os mais usados para produção de pedra britada (FRAZÃO, 2007).

Apesar de a pedra apresentar naturalmente requisitos de maior resistência e durabilidade, sua seleção requer cuidados. Devido à alta gama de variedades, sempre existirá a mais apta a atender às exigências de uma dada obra. Cabe aos engenheiros saber fazer uma seleção judiciosa daquelas que melhor atenderão aos objetivos pretendidos para elas no projeto (TANNÚS, 2007).

A extração e o desmonte de rochas na pedreira são feitos por explosivos em blocos com dimensões que facilitem o transporte por caçambas para os britadores e peneiras. A produção de agregado natural para construção civil envolve diversos fatores: tipo de uso da pedra, características das jazidas, tipo de equipamento e propriedades da rocha. Esses fatores, dentre outros, são geralmente interdependentes e definem o tipo de trabalho a ser adotado para cada ocasião.

A instalação de pedreiras para produção de agregados apresenta duas finalidades: uma, somente comercial, para atender à demanda de uma cidade ou de uma região; e outra, para suprimento de material para uma dada obra (ou conjunto de obras). A distância entre a pedreira e o mercado consumidor, ou uma determinada obra, deve ser a menor possível, para baratear os custos de transportes (FRAZÃO, 2007).

A britagem consiste da quebra de partículas, principalmente pela ação de esforços compressivos ou de impacto. Os esforços compressivos são aplicados, em geral, por meio do movimento periódico de aproximação e afastamento de uma superfície móvel contra outra fixa. Esse é o caso dos britadores de mandíbulas, britadores giratórios e britadores cônicos (HONÓRIO, 2010).

\subsection{Agregado reciclado}

O agregado reciclado é obtido a partir de Resíduos de Construção e Demolição, e são divididos em classes, conforme resolução do (CONAMA, 2012), os resíduos da construção civil deverão ser classificados como: Classe A, B, C e D.

Os Classificados como Classe A, são os resíduos reutilizáveis ou recicláveis como agregados, tais como: de construção; demolição; reformas e reparos de pavimentação e de outras obras de infraestrutura; inclusive solos provenientes de terraplanagem; componentes cerâmicos (tijolos, blocos, telhas e placas de revestimento); argamassa e concreto; de processo de fabricação e/ou demolição de peças pré-moldadas em concreto (blocos, tubos, meio-fio) produzidas nos canteiros de obras.

A maior problemática relacionada ao uso do Resíduo de Construção e Demolição - RCD como agregado na construção civil, está ligada à sua coleta e separação na fonte geradora, que muitas vezes é descartado de forma inadequada. Aos poucos, uma política ambiental vem sendo introduzida nos canteiros de obras, com a finalidade de conscientizar os profissionais sobre a importância do descarte adequado desses materiais.

Outros fatores que dificultam a utilização dos agregados reciclados estão ligados a qualidade do agregado produzido, tais como: forma do agregado, granulometria e quantidade de finos. Além desses fatores, um dos fatores relevantes é a quantidade de argamassa aderida ao agregado, chamada de "argamassa velha" do agregado reciclado, que se torna um fator influente na porosidade e durabilidade do concreto.

Conforme (MESQUITA et al., 2015), a reciclagem na construção civil pode gerar muitos benefícios, com reflexo direto na redução do consumo de recursos naturais não renováveis. Alternativas sustentáveis têm sido avaliadas em relação à utilização dos resíduos de construção e demolição reciclados (RCD-R), como agregados em obras de pavimentação, na produção de argamassas, blocos 
e artefatos de concreto, em sistemas de drenagem, obras de contenção, entre outros. A forma mais difundida de tratamento dos RCD's, consiste na segregação da fração mineral, que é triturada até a granulometria desejada, para posteriormente ser utilizada na indústria da construção civil.

Segundo (BUTTLER et al., 2006), no ano de 2006, existiam apenas 18 instalações de reciclagem públicas e privadas com escala de produção pequena (cerca de 100t/dia de resíduos processados), no Brasil. Algumas estimativas indicavam um montante de 68,5 a 106 toneladas de resíduos de construção e demolição/ano, sendo que, com as instalações em operação no país, à época, apenas $1 \%$ desse montante poderá ser reciclado. Com esses dados, pode-se aferir que o Brasil apresentava em 2006 um déficit de pelo menos 2600 usinas de reciclagem que seriam necessárias para processar o volume de resíduos gerados (BUTTLER et al., 2006).

Devido ao déficit de instalações de reciclagem e ao elevado custo de transporte, algumas empresas privadas e fábricas de pré-moldados estão investindo na aquisição de equipamentos de reciclagem com o intuito de reciclar os resíduos de concreto na própria fonte de geração (BUTTLER et al., 2006). Desta forma, a triagem dos resíduos pode ser melhor aplicada, eliminando os contaminantes tão indesejáveis. E influenciando o principal agente causador do RCD, a mão de obra da indústria da construção civil, pode-se iniciar uma corrente de sustentabilidade na construção.

A composição do RCD, oriundo de cada uma das atividades que compõem os trabalhos da construção civil, é diferente, e também em cada etapa da obra, mas sempre há um produto que se sobressai, que é diferente em cada região, em razão da diversidade de tecnologias construtivas e de matérias-primas utilizadas na região (FERREIRA, 2013). Sendo assim, o uso do RCD-R requer estudos continuados que possam contribuir para o avanço da indústria da construção e da sustentabilidade no setor.

\section{Produção do agregado graúdo}

As características do agregado britado são influenciadas pelas condicionantes do processo de extração e fabricação, tais como uso de explosivos e tipos de britadores (MEHTA; MONTEIRO, 2008).

Os britadores mais comuns são os de mandíbulas, que apresentam movimentos alternados (de simples efeito e de duplo efeito). Outros tipos de britadores apresentam movimento contínuo (giratório ou de rolos). Após a fragmentação, a rocha passará por um processo de britagem, que consiste em reduzir suas dimensões a tamanhos utilizáveis, para material de construção. Para execução de britagem, podem ser utilizados britadores de diversos tipos. A escolha do tipo de britador é baseada nas características físicas e mecânicas da rocha, na capacidade de produção (qualitativa e quantitativa), na facilidade de funcionamento e de manutenção e na facilidade de montagem, de desmonte e de substituição de peças (FRAZÃO, 2007).

\subsection{Britagem do agregado natural}

Quando uma rocha é submetida à fragmentação por processos mecânicos de britagem, o produto será constituído de fragmentos com formas e dimensões variadas. Os tipos de forma que ocorrem na rocha britada recebem diferentes designações: cúbicas (ou esférica), alongada (ou prismática), alongadalamelar e lamelar (ou achatada, ou discóide) (SILVA, 2012).

Figura 1 Projeção da forma ideal da partícula sobre a verdadeira (forma equidimensional)

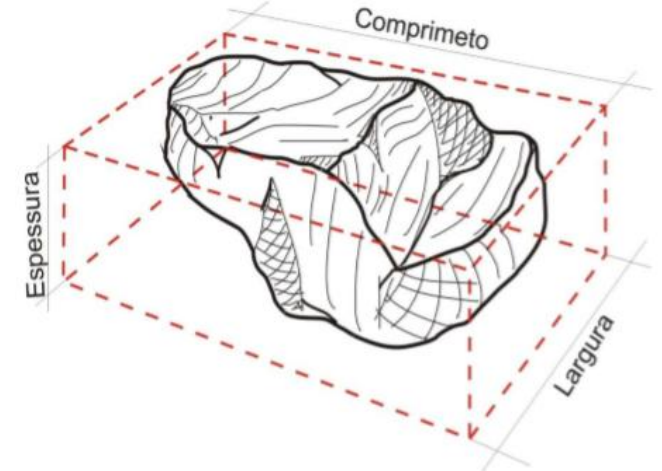

Fonte: (SILVA; GEYER, 2018b) 
Estudos desenvolvidos por (SILVA; GEYER, 2018b) classificam a forma do agregado graúdo britado em quatro categorias (cúbica, alongada, alongada-lamelar e lamelar). Como resultado de sua pesquisa, há uma porcentagem de cada forma em uma determinada amostra analisada, sendo a forma cúbica predominante no processo de britagem.

Quando uma partícula é submetida a esforços mecânicos superiores à sua resistência, há a ruptura, ocorre a propagação de trincas já existentes e a iniciação de novas trincas em seu interior, o que causa a fragmentação da partícula. Os esforços mecânicos aplicados podem ser normais (compressão ou tração) ou tangenciais (cisalhamento). A resposta de qualquer sólido a aplicação de tais esforços se dá na forma de deformações, as quais podem ser classificadas como elásticas e inelásticas (HONÓRIO, 2010).

Segundo (HONÓRIO, 2010), durante a fragmentação, as forças de contato deformam as partículas criando um campo de tensões, e as partículas respondem criando trincas ou se deformando de maneira inelástica. Esse processo pode ocorrer pelos mecanismos de abrasão, clivagem ou estilhaçamento, os quais dependem do nível de energia aplicada.

Os materiais rochosos, em sua maioria, se deformam de forma elástica, até muito próximo do instante de sua ruptura. Entretanto, em alguns casos, podem apresentar comportamento inelástico, caracterizando-os como elasto-plásticos, caso em que o resultado da aplicação de esforços é a deformação permanente do material (SILVA, 2012).

Segundo (MEHTA; MONTEIRO, 2008), as características do agregado britado dependem da microestrutura da rocha matriz, expressas pela sua porosidade, massa específica e composição mineralógica, bem como de sua exposição prévia (grau de intemperismo). Calcários laminados, arenitos e folhelhos tendem a produzir fragmentos alongados e achatados (SILVA, 2012).

Segundo (FRAZÃO, 2007), rochas de origem metamórficas com estruturas orientadas ou bandadas, quando britadas, apresentam boas características físicas e mecânicas, mas uma indesejável frequência de fragmentos achatados e alongados. A forma dos fragmentos é influenciada pela estrutura da rocha e, em menor grau, por sua textura. As rochas com estrutura marcadamente estratificada, bandadas ou xistosas tendem a produzir formas lamelares e alongadas, tais como alguns quartzitos, arenitos estratificados, silicificados, gnaisses e xistos. As rochas de estrutura maciça tendem a apresentar uma frequência maior de fragmentos de forma cúbica.

\subsection{Britagem do agregado reciclado}

$O$ processo de beneficiamento pode também ser uma alternativa para se obterem agregados reciclados com características apropriadas. O estudo realizado por (GOMES et al., 2015) demonstra que a fragmentação de agregados por diferentes processos reduz a porosidade do material e, muitas vezes, favorecem a obtenção de características similares às do material natural (CORDEIRO et al., 2017). A massa específica dos agregados graúdos provenientes de RCD-R reciclado podem variar entre $2,67 \mathrm{~g} / \mathrm{cm}^{3}$ e $2,72 \mathrm{~g} / \mathrm{cm}^{3}$, conforme estudos realizados por (SILVA; ARNOSTI, 2005), e esta unidade pode ser influenciada pelo processo de britagem (SILVA; GEYER, 2018b).

Em estudos realizados por (GOMES et al., 2015) demonstram que os agregados de concreto reciclados possuem pasta de cimento porosa aderida à superfície dos grãos reciclados, mostrado esquematicamente na figura 2 . Os agregados utilizados para o experimento sobre agregado reciclado não obtiveram a forma original, não sendo possível visualizar a forma dos agregados naturais utilizados no concreto original após o processo de britagem, devido à alta quantidade de argamassa aderida "argamassa velha". 
Figura 2 Detalhe agregado reciclada com argamassa aderida

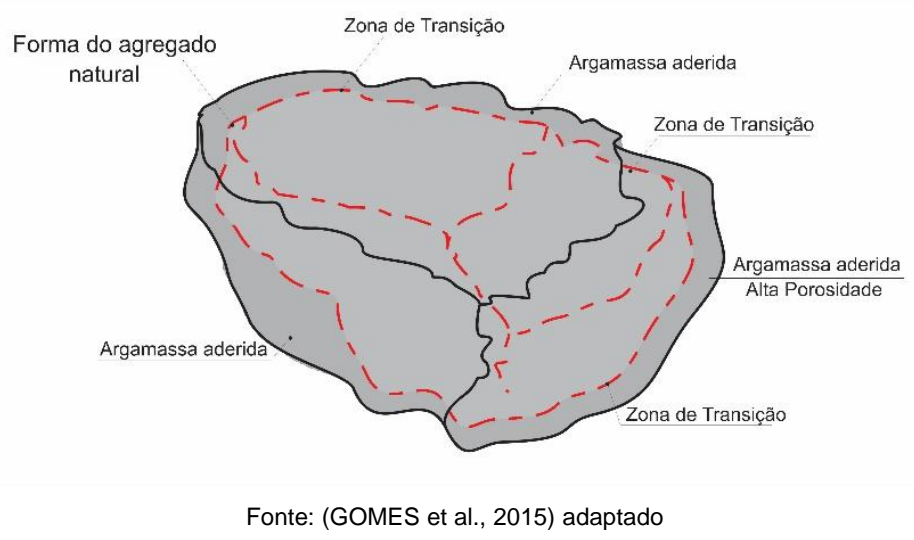

Estudos foram realizados por (SILVA; GEYER, 2018a), sobre a influência da forma do agregado graúdo britado nas propriedades do concreto. O referido estudo apresenta informações pertinentes sobre o processo de britagem e sua relação com a forma das partículas. Quanto menor a massa unitária do agregado, maior o percentual de partículas irregulares "partículas indesejadas para a produção de concreto" (SILVA; GEYER, 2018b).

Britadores de eixo vertical apresentam resultados mais satisfatórios em relação a forma adequada das partículas para produção de concretos, conforme experimento apresentado por (SILVA, 2012). Com relação a mistura dos materiais em britadores com eixo vertical, (CORDEIRO et al., 2017) apresentou resultados semelhantes. Seus estudos mostram que ocorreu desagregação de partículas nas misturas realizadas em misturador de eixo vertical, para análise do comportamento entre o agregado natural $\mathrm{e}$ reciclado. Para a betoneira de eixo inclinado, a granulometria permaneceu praticamente inalterada, tanto para a ordem de mistura tradicional, quanto para a ordem de mistura modificada.

Estudos de Ulsen et al., (2013) confirmaram que mais estágios de britagem resultam em uma redução da absorção de água do agregado graúdo reciclado em aproximadamente $10 \%$ a $20 \%$, comparados com o uso de uma e duas etapas de britagem. Já uma terceira etapa por um britador de eixo vertical obteve uma redução de $40 \%$ a $60 \%$ na absorção de água do agregado reciclado.

\section{Influência da britagem sobre o agregado graúdo}

\subsection{Agregado natural}

A rocha submetida à fragmentação mecânica produz fragmentos com diferentes tamanhos e formas. $\mathrm{A}$ forma dos agregados é bastante influenciada pela estrutura e textura da rocha mãe. Rochas de estruturas maciças, como os basaltos compactos, produzem britas de formas cúbicas. Por outro lado, rochas com estrutura xistosa, como é típico em rochas sedimentares e alguns tipos de rochas metamórficas, formada a partir destas, com frequência produzem fragmentos de formas alongadas e lamelares. O processo de britagem exerce muita influência no formato dos agregados (NUNES; MARQUES, 2007).

Segundo (EDUARDO, 2002), a forma do agregado graúdo depende da rocha de origem e do tipo de britador. $\mathrm{O}$ agregado britado pode conter uma proporção considerável de partículas lamelares ou alongadas, que afetam negativamente as propriedades do concreto.

A britagem do agregado graúdo tende a produzir fragmentos alongados e achatados, especialmente quando o mesmo é feito por britadores de mandíbulas. Aquelas partículas, cuja espessura é pequena em relação às outras duas dimensões, são chamadas de lamelares ou achatadas (MEHTA; MONTEIRO, 2008).

Segundo (SBRIGH; FRAZÃO, 1984), há uma diminuição da porcentagem de fragmentos cúbicos com a redução da granulometria. Porém, a diminuição da cubicidade com a redução granulométrica devese, possivelmente, às condições de britagem e às características petrográficas intrínsecas do material. A fração granulométrica acima de 2" (50mm), contém uma nítida predominância de cubicidade. 
Britadores de mandíbula tendem a produzir partículas lamelares ou achatadas devido ao mecanismo de compressão. Já os britadores de eixo vertical e eixo inclinado tendem a produzir partículas cúbicas ou esféricas devido ao desgaste das arestas pelo atrito nas paredes do britador. Estudos realizados por (SILVA; GEYER, 2018a) relatam que quanto menor a granulometria do agregado, maior será a quantidade de partículas lamelares "partículas indesejadas" para a produção de concreto.

\subsection{A agregado reciclado}

Pode-se deduzir com base nos estudos de (SILVA, 2012), que essa desagregação relatada por (CORDEIRO et al., 2017), é proveniente de argamassa aderida, "argamassa velha", que se desprende do agregado reciclado, como resultado da energia aplicada da betoneira de eixo vertical e o atrito com outros agregados, produzindo uma maior quantidade de agregados finos.

De acordo com (NAGATAKI et al., 2004; SILVA; GEYER; PANTOJA, 2017b), a tecnologia de reciclagem influencia significativamente nas propriedades do agregado. Nos estudos de (NAGATAKI et al., 2004), foi utilizado uma combinação de britador de mandíbula e britador de impacto para processar o material triturado duas vezes, com um equipamento mecânico de moagem para minimizar a argamassa aderida - AD.

Em uma análise microscópica de varredura em concretos produzidos com várias fases de britagem, houve redução considerável da densidade das rachaduras no agregado reciclado, eliminando as partículas com micro defeitos e vazios irregulares e processando até novas fissuras. Apenas uma quantidade muito pequena de rachaduras pode ser detectada na argamassa aderida ou na zona de transição interfacial. Consequentemente, os agregados de concreto reciclado obtidos de vários estágios de processos de reciclagem não apresentaram perda de integridade. Além disso, a extensão do processo de reciclagem até aumentou eficientemente o desempenho físico do agregado de concreto, reduzindo a argamassa aderente (NAGATAKI et al., 2004).

A fragmentação por diferentes estágios dos britadores remove parcialmente a antiga pasta de cimento aderida dos agregados reciclados e, assim, reduz a porosidade do concreto produzido com agregado reciclado (TAM; GAO; TAM, 2005; ULSEN et al., 2013).

Estudos realizados por (NAGATAKI et al., 2004) mostraram que os usos de três estágios de britagem levaram a uma redução da absorção de água do concreto com agregado graúdo britado em torno de $35 \%$ a $50 \%$, comparando com concretos produzidos com agregados britados em primeiro e segundo estágios de britagem.

Para o beneficiamento do agregado reciclado, britagem, moagem, desmonte e processos de trituração, dentre vários outros, uns podem produzir agregados de melhor qualidade, segundo a forma, quantidade de argamassa aderida e quantidade de impurezas. Com base nos estudos de (GOMES et al., 2015), o processo de britagem em várias fases produzem agregados com menor quantidade de argamassa aderida "argamassa velha". Essa argamassa se desprende devido a moagem do mecanismo de atrito, causando um aumento na quantidade de finos. Estes finos provenientes da argamassa de concreto e concreto estrutural, quando reciclados, contém finos em fase anidra "não hidratada". Estes resultados podem ser relacionados ao alto consumo de cimento nos concretos estruturais de aproximadamente $350 \mathrm{~kg} / \mathrm{m}^{3}$, e que devido à falta de controle tecnológico na produção do concreto a/c não consegue hidratar $100 \%$ do aglomerante hidráulico. Sendo assim, fica uma pequena parcela na mistura do concreto em fase anidra.

Conforme (CORDEIRO et al., 2017), apresenta um processo de mistura em três etapas. A primeira visa umidificar o agregado graúdo reciclado. A segunda objetiva tratar a superfície do agregado com o cimento, tal qual a proposta de (GOMES; DE BRITO, 2009; TAM; GAO; TAM, 2005; TAM; TAM, 2008), além de garantir que o agregado reciclado absorva a água da mistura. Já a terceira, na qual é adicionado o restante dos materiais necessários para a produção do concreto, visa homogeneizar a mistura até atingir a consistência desejada.

\section{Comparativo das características do agregado natural e agregado reciclado}

A massa específica dos agregados graúdos provenientes de RCD-R reciclado podem variar entre 2,48 $\mathrm{g} / \mathrm{cm}^{3}$ e $2,72 \mathrm{~g} / \mathrm{cm}^{3}$ conforme estudos realizados por (SILVA; ARNOSTI, 2005). Já para agregados rochosos naturais a massa especifica pode variar entre $2,57 \mathrm{~g} / \mathrm{cm}^{3}$ e $2,72 \mathrm{~g} / \mathrm{cm}^{3}$, conforme a forma da partícula, e esta unidade pode ser influenciada pelo processo de britagem (SILVA; GEYER, 2018a). 
Conforme estudo realizado por (GONÇALVES, 2001) sobre agregados reciclados de resíduos de concreto, onde compara os resultados da caracterização dos agregados reciclado e agregado natural para concreto, apresentam resultados semelhantes com (SILVA; ARNOSTI, 2005).

Tabela 1 Comparativo das características do agregado graúdo natural e artificial

\begin{tabular}{lcc}
\multicolumn{1}{c}{ Caracterização do agregado } & \multicolumn{2}{c}{ Resultado } \\
\cline { 2 - 3 } & $\begin{array}{c}\text { Agregado } \\
\text { Natural }\end{array}$ & $\begin{array}{c}\text { Agregado } \\
\text { Reciclado }\end{array}$ \\
\hline Massa unitária NBR 7251 (ABNT, 1982) & $1.480 \mathrm{~kg} / \mathrm{m}^{3}$ & $1.290 \mathrm{~kg} / \mathrm{m}^{3}$ \\
\hline $\begin{array}{l}\text { Massa específica na condição seca NBR NM } \\
53 \text { (ABNT, 2003) }\end{array}$ & $2.830 \mathrm{~kg} / \mathrm{m}^{3}$ & $2.480 \mathrm{~kg} / \mathrm{m}^{3}$ \\
\hline $\begin{array}{l}\text { Massa específica na condição saturada } \\
\text { superfície seca NBR NM 53 (ABNT, 2003) }\end{array}$ & $2.880 \mathrm{~kg} / \mathrm{m}^{3}$ & $2.610 \mathrm{~kg} / \mathrm{m}^{3}$ \\
\hline Índice de vazios NBR 9778 (ABNT, 2017) & $5,50 \%$ & $12,30 \%$ \\
\hline Absorção de água NBR NM 53 (ABNT, 2003) & $1,40 \%$ & $4,40 \%$ \\
\hline 30 min & $1,90 \%$ & $4,90 \%$ \\
\hline \multicolumn{2}{c}{ Fonte: (GONÇALVES, 2001) adaptado } \\
\hline
\end{tabular}

Em estudos realizados por (LINTZ et al., 2012). Em análise dos dados provenientes dos ensaios de caracterização, pode-se observar que os agregados naturais possuem massa especifica e massa unitária maiores que os agregados reciclados, confirmado os resultados encontrados por outros pesquisadores como (GOMES; DE BRITO, 2009; HANSEN, 1986; TAM; GAO; TAM, 2005). Os agregados reciclados possuíam menor massa específica e maior absorção de água que o agregado natural.

\section{Concreto com agregado reciclado}

O fator preponderante da utilização de agregados reciclados em concretos é a elevada absorção de água e o enfraquecimento da zona de transição agregado/pasta de cimento e a baixa resistência do agregado. Segundo a metodologia apontada por (GOMES; DE BRITO, 2009; TAM; GAO; TAM, 2005), divide-se em duas etapas a hidratação da pasta, sendo a primeira com o objetivo de envolver o agregado, possibilitando a sucção da pasta hidratada aos poros e aberturas do agregado reciclado. $\mathrm{Na}$ segunda etapa ocorre a cristalização, diminuindo a porosidade do agregado e do concreto como um todo. A segunda adição de água serve para hidratar o resto do cimento necessário para a composição do concreto, minimizando a porosidade da argamassa aderida ao agregado reciclado, elemento influenciador na porosidade do concreto com agregados reciclados. $\mathrm{Na}$ argamassa aderida em agregados reciclados (argamassa velha) formam restos de argamassa, que no processo de trituração não foi possível descolar/separar do agregado reciclado.

Estudos sobre o concreto reciclado indicaram que a zona de transição ZT é o elo mais fraco no concreto, interface entre a pasta de cimento e a AR (NAGATAKI et al., 2004). Portanto, a modificação da microestrutura na ZT tem sido uma das grandes preocupações para melhorar as propriedades do CR (KONG et al., 2010). Estudos (NAGATAKI et al., 2004), (KONG et al., 2010) têm demonstrado que, tanto a ZT entre a AR e a nova matriz de cimento, formam o elo fraco do concreto e afetam as propriedades mecânicas do concreto. Porém um aperfeiçoamento tecnológico pode ser feito como melhoria no concreto através de um "pré-tratamento do agregado reciclado AR com solução de sílica ativa, $10 \%$ em peso" (KATZ, 2004). Segundo estudos sobre o processo de britagem demostra que este tratamento pode aumentar em torno de $15 \%$ a $30 \%$ a resistência à compressão nas idades de 7 e 28 dias. No entanto, o processo de pré-tratamento antes da produção de concreto levará a um custo mais alto, limitando assim sua aplicação na construção.

Conforme estudos relatados por (ULSEN et al., 2013) confirmou que mais estágios de britagem resultam em uma redução da absorção de água do agregado graúdo reciclado em aproximadamente $10 \%$ a $20 \%$, comparados com o uso de uma e duas etapas de britagem. Já uma terceira etapa, utilizando um britador de eixo vertical, obtiveram uma redução de $40 \%$ a $60 \%$ na absorção de água do agregado reciclado. 


\section{Conclusão}

A qualidade do agregado graúdo natural depende de fatores internos e externos, como: formação da rocha, origem da rocha, composição mineralógica e processo de britagem. Britadores de eixo vertical e eixo inclinado, na britagem secundária e terciária, produzem partículas de forma mais quadrada ou arredondada e um aumento na produção de agregado miúdo e materiais pulverulentos. Isso ocorre devido ao processo mecânico do eixo rotor, que provoca o atrito das partículas na superfície metálica do equipamento e o atrito com outras partículas, levando ao desgaste e lapidagem do agregado. No caso do agregado reciclado de concreto, há uma maior retirada da argamassa velha (argamassa aderida). Nos agregados cerâmicos são extraídas as partes mais frágeis, permanecendo em sua maior parte, agregados resistentes.

Britadores primários tendem a produzem partículas lamelares e alongadas que são frágeis e facilmente quebráveis, prejudicando a obtenção de maiores resistências no concreto. Além disso, a angulosidade acentuada das partículas provoca o aumento no consumo de água necessária para uma dada trabalhabilidade. Por fim, com o aumento no tamanho e quantidade de partículas lamelares e alongadas, associadas ao acúmulo de água próximo à superfície do agregado, há o enfraquecimento da aderência na zona de transição para concretos com agregados rochosos naturais.

A qualidade do agregado reciclado, por sua vez, depende de fatores externos e internos das usinas de reciclagem. Entre os fatores externos estão a técnica de esmagamento do britador, a uniformidade mineral apresentada pelo RCD e a armazenagem do mesmo em canteiro de obra.

Pode-se concluir que a baixa massa especifica e baixa massa unitária do agregado reciclado em comparação ao agregado natural, é atribuído a alta quantidade de argamassa aderida a superfície da partícula que não foi removida no processo de britagem do agregado. Estudos relatam, que mais processos de britagem, britagem secundaria e terciaria tendem a eliminar a argamassa aderida nas partículas recicladas.

\section{Referências}

ABNT. NBR 7211 - Agregados para concreto - EspecificaçãoRio de Janeiro - RJAssociação Brasileira de Normas Técnicas, , 2005. Disponível em: <www.abnt.org.br>

ABNT NBR 9778. Argamassa e concreto endurecidos - Determinação da absorção de água, índice de vazios e massa específica, 2017.

ABNT NM 53. Agregado graúdo - Determinação de massa específica, massa específica aparente e absorção de água - ABNT NM 53,Rio de Janeiro, 2003. Disponível em: $<$ http://professor.pucgoias.edu.br/SiteDocente/admin/arquivosUpload/17827/material/Nbr_nm53_2003. pdf>

AïTCIN, P. C. Concreto de alto desempenho. Tradução de Geraldo G. Serra. p. 667, 2000.

ALVES, A. V. et al. Mechanical properties of structural concrete with fine recycled ceramic aggregates. Construction and Building Materials, v. 64, p. 103-113, 14 ago. 2014.

AMORIM, P.; BRITO, J. DE. Concrete Made With Coarse Concrete Aggregate: ACI Materials Journal, v. 109, n. March, p. 195-204, 2012.

BRAVO, M. et al. Durability performance of concrete with recycled aggregates from construction and demolition waste plants. Construction and Building Materials, v. 77, p. 357-369, 2015.

BUTTLER, A. M. et al. Blocos Estruturais De Concreto Com Agregados Reciclados De Concreto Caracterização Das Propriedades Físicas. Entac. Anais...2006

CONAMA. Resolução $n^{\circ}$ 307, de 5 de julho de 2002, do Conselho Nacional do Meio AmbienteCONAMA., 2012.

CORDEIRO, L. DE N. P. et al. Avaliação de processos de misturas de concretos com agregados graúdos reciclados. Ambiente Construído, v. 17, n. 3, p. 255-265, 30 jun. 2017.

EDUARDO, M. S. Estudo experimental de concreto de alto desempenho utilizando agregados graúdos disponíveis na região Metropolitana de Curitiba. [s.l.] Universidade Federal do Parana, 2002.

FERREIRA, E. T. Contribuição ao estudo do potencial de aproveitamento de agregados reciclados de RCC produzidos na Usiben - João Pessoa - em concreto estrutural aplicado em lajes pré-moldadas. [s.I.] Universidade Federal da Baia, Salvador - BA, 2013.

FRAZÃO, E. B. Tecnologia para produção e utilização de agregados: Agregados para Construção Civil 
no Brasil. 2007.

GOMES, M.; DE BRITO, J. Structural concrete with incorporation of coarse recycled concrete and ceramic aggregates. Portugal Sb07 - Sustainable Construction, Materials and Practices: Challenge of the Industry for the New Millennium, Pts 1 and 2, p. 887-894, 2007.

GOMES, M.; DE BRITO, J. Structural concrete with incorporation of coarse recycled concrete and ceramic aggregates: Durability performance. Materials and Structures/Materiaux et Constructions, v. 42, n. 5, p. 663-675, jun. 2009.

GOMES, P. C. C. et al. Comminution and sizing processes of concrete block waste as recycled aggregates. Waste Management, v. 45, p. 171-179, 26 jan. 2015.

GONÇALVES, R. D. C. C. Agregados Reciclados De Resíduos De Concreto - Um Novo Material Para Dosagens Estruturais. p. 148, 2001.

HANSEN, T. C. Recycled aggregates and recycled aggregate concrete second state-of-the-art report developments 1945-1985. Materials and Structures, v. 19, n. 3, p. 201-246, 1986.

HONÓRIO, O. ESTUDO DE AUMENTO DE CAPACIDADE DA PLANTA DE BRITAGEM DA USINA I DE GERMANO. 2010.

KATZ, A. Treatments for the improvement of recycled aggregate. Journal of Materials in Civil Engineering, v. 16, n. 6, p. 597-603, nov. 2004.

KONG, D. et al. Effect and mechanism of surface-coating pozzalanics materials around aggregate on properties and ITZ microstructure of recycled aggregate concrete. Construction and Building Materials, v. 24, n. 5, p. 701-708, 2010.

LINTZ, R. C. C. et al. Study of the reuse of construction residues in concrete employed by blocks manufacture. Revista IBRACON de Estruturas e Materiais, v. 5, n. 2, p. 166-181, 2012.

M. C. POWERS. A New Roundness Scale for Sedimentary Particles. SEPM Journal of Sedimentary Research, v. Vol. 23, n. 2, p. 117-119, 1953.

MARTINS, D. J.; CORREIA, J. R.; DE BRITO, J. The effect of high temperature on the residual mechanical performance of concrete made with recycled ceramic coarse aggregates. Fire and Materials, v. 40, n. 2, p. 289-304, 1 mar. 2016.

MEHTA, P. K.; MONTEIRO, P. J. M. Concreto: estrutura, propriedades e materiais. In: $3^{\text {a }}$ ed. ed. São Paulo - SP: Editora Pini, 2008. p. 573.

MENDES, S. E. D. S. Summary for Policymakers. In: INTERGOVERNMENTAL PANEL ON CLIMATE CHANGE (Ed.). . Climate Change 2013 - The Physical Science Basis. Cambridge: Cambridge University Press, 2002. p. 1-30.

MESQUITA, L. C. et al. ANÁLISE DA VIABILIDADE TÉCNICA DE UTILIZAÇÃO DE RESÍDUOS DE CONSTRUÇÃO E DEMOLIÇÃO NA FABRICAÇÃO DE BLOCOS DE VEDAÇÃO. REEC - Revista Eletrônica de Engenharia Civil, p. Volume 10, № 3, 30-40, 2015.

NAGATAKI, S. et al. Assessment of recycling process induced damage sensitivity of recycled concrete aggregates. Cement and Concrete Research, v. 34, n. 6, p. 965-971, 2004.

NBR ABNT 7251. Agregado em estado solto - Determinação da massa unitária -Rio de Janeiro, 1982.

NUNES, M. F.; MARQUES, E. P. Agregados para a construção civil: Materiais de construção civil e princípios da ciência e eng. de materiais. In: [s.l: s.n.]. v. 01p. 481-524.

O'REILLY, V. A. Método de dosagem de concreto de elevado desempenho. In: TRADUÇÃO: AVELINO A. DE PÁDUA, L. T. S. E N. D. B. (Ed.). . Pini ed. São Paulo - SP: 1998, 1998.

PARAGUASSU, A. B.; FRAZÃO, E. B. Materiais Rochosos para Construção. Associação Brasileira de Geologia de Eng. Ambienta, v. Único, n. São Paulo, p. 331- 342., 1998.

SBRIGHI NETO, C; FRAZÃO, E. B. The influence of the shape of the coarse aggregate on some hydraulic concrete properties. International Symposium on Aggregates - Bulletin IAEG, n 30 . Anais...1984

SILVA, D. DE A. E. Estudo da Influência do Índice de Forma do Graúdo nas Propriedades Mecânicas do Concreto. [s.I.] Dissertação de (Mestrado) - Universidade Federal de Goiás, Escola de Engenharia Civil, 2012.

SILVA, D. DE A.; GEYER, L. B. Influência da Forma do agregado graúdo nas propriedades mecânicas do concreto. Revista Científica Multidisciplinar Núcleo do Conhecimento, v. 05, n. 12, p. 67-82, 2018a.

SILVA, D. DE A.; GEYER, L. B. Analise e classificação da forma do agregado graúdo britado para 
concreto. Revista Científica Multidisciplinar Núcleo do Conhecimento, v. 05, n. 12, p. 18-28, 2018b.

SILVA, D. DE A.; GEYER, L. B.; PANTOJA, J. DA C. Estudo da Forma do Agregado Graúdo e Sua Influência no Módulo de Elastricidade do Concreto. XIII Congresso Internacional Sobre Patologia e Reabilitação de Estruturas. Anais...2017a

SILVA, D. DE A.; GEYER, L. B.; PANTOJA, J. DA C. Porosidade do Concreto Versus Forma do Agregado graúdo. XIII Congresso Internacional Sobre Patologia e Reabilitação de Estruturas. Anais...Crato - CE, Brasil: 2017b

SILVA, R. W. .; ARNOSTI, J. S. Caracterização Do Resíduo De Construção E Demolição ( Rcd ) Reciclado Characterization of the Construction and Demolition Wastes ( Rcd ) Recycled. Holos Environment, v. 5, n. 2, p. 137-151, 2005.

SILVA, R. V.; DE BRITO, J.; DHIR, R. K. Properties and composition of recycled aggregates from construction and demolition waste suitable for concrete production. Construction and Building Materials, v. 65, p. 201-217, 29 ago. 2014.

STROHER, A. P. et al. UTILIZAÇÃO DA CERÂMICA DE ENTULHO NA SUBSTITUIÇÃO DE AGREGADO GRAÚDO DO CONCRETO. Cerâmica Industrial, v. 22, n. 4, p. 34-46, 2017.

TAM, V. W. Y.; GAO, X. F.; TAM, C. M. Microstructural analysis of recycled aggregate concrete produced from two-stage mixing approach. Cement and Concrete Research, v. 35, n. 6, p. 11951203, jun. 2005.

TAM, V. W. Y.; TAM, C. M. Diversifying two-stage mixing approach (TSMA) for recycled aggregate concrete: TSMAs and TSMAsc. Construction and Building Materials, v. 22, n. 10, p. 2068-2077, out. 2008.

TANNÚS, M. B. Tecnologia para produção e utilização de agregados: Contribuição de Políticas Públicas. 2007.

ULSEN, C. et al. Production of recycled sand from construction and demolition waste. Construction and Building Materials, v. 40, p. 1168-1173, 2013. 